\title{
Effects of Visual Impairment on the Quality of Life of Children Aged 8 to 18 Years in a Tertiary Referral Center
}

\author{
Catherine Joanne B. Valconcha, MD, ${ }^{1}$ Marissa N. Valbuena, MD, MHPEd ${ }^{1,2}$ and James Abraham B. Lee, MD ${ }^{1,2}$ \\ ${ }^{1}$ Department of Ophthalmology and Visual Sciences, Philippine General Hospital, University of the Philippines Manila \\ ${ }^{2}$ College of Medicine, University of the Philippines Manila
}

\begin{abstract}
Background. Vision impairment impacts children's physical well-being, psychological state, and productivity. The Impact of Vision Impairment for Children (IVI_C) is a vision-specific pediatric instrument designed to assess the effects of visual impairment on the quality of life (QoL) in children aged 8 to 18 years who have no additional disabilities. It measures quality of life to assess the needs of children with low vision and outcomes of interventions by deriving answers from both children and their caregivers.
\end{abstract}

Objectives. The primary objective of the study was to determine the effect of visual impairment on the quality of life of children aged 8 to 18 years.

Methods. This was an observational, analytical, cross-sectional study conducted at the Outpatient Department of the University of the Philippines-Philippine General Hospital, Sentro Oftalmologico Jose Rizal (SOJR), General and Pediatric Ophthalmology Clinics. We included children 8 to 18 years of age with best corrected visual acuity of less than or equal to $20 / 40$ in the better-seeing eye for the visually impaired (VI) group. The control group included children aged 8 to 18 years with best corrected visual acuity of 20/20 to 20/30 in both eyes. Participants underwent a complete ophthalmologic examination, including the determination of visual acuity using the Early Treatment Diabetic Retinopathy Study (ETDRS) chart prior to administration of the Filipino version of IVI_C questionnaire. After the ophthalmologic examination and prior to end of the medical consultation, the investigator administered the questionnaire to the children and their parents.

Results. A total of 133 participants were included in the study, 67 in the visually impaired group and 66 in the control group. Participants had a median age of 10 years (range, 8 to 18), and 54\% were female. Overall QoL scores and sub-scores across domains were significantly lower in the visually impaired group compared to the control group. The mean total and domain IVI_C scores progressively declined with increasing severity of visual impairment. The mean $( \pm S D)$ total score ranged from $56 \pm 6$ in the mildly impaired to $42 \pm 8$ in the severe bilateral impairment group. On multivariate analysis, the significant predictors of quality of life were visual impairment and age. Quality of life of children with visual impairment is lower by 33.59 points $(95 \% \mathrm{Cl}-35.82$ to -31.36$)$ than those in the control group. The QoL score increased by 0.579 per one unit increase in age. This model explained $87.05 \%$ of the variance in the IVI_C scores $(p<0.01)$.

Conclusion. Children with visual impairment have significantly decreased IVI_C and quality of life scores, overall and across domains. Lower scores are associated with increased severity of visual impairment.

Keywords: Pediatric ophthalmology, visual impairment, quality of life, children, quality of life questionnaire

\section{INTRODUCTION}

Corresponding author: Catherine Joanne B. Valconcha, MD Department of Ophthalmology and Visual Sciences Philippine General Hospital

University of the Philippines Manila

Taft Avenue, Ermita, Manila 1000, Philippines

Email: catevalconcha@yahoo.com
Vision impairment (VI) significantly affects children, as well as their caregivers and their families. It can affect the child's development, quality of life (QoL), education and the care given by their families and medical professionals. ${ }^{1}$ Vision impairment impacts children's physical well-being, psychological state, and productivity. ${ }^{2}$ Quality of life has been defined by the World Health Organization as an "individual's 
perception of their position in life in the context of the culture and value systems in which they live, and in relation to their goals, expectations, standards, and concerns." It is an important state of health and well-being, and may largely be defined by one's degree of physical health. ${ }^{3}$

The support needed for vision-impaired children includes their physical and psychological needs. In addition to clinical and functional vision tests, it is necessary to assess children's ability to socialize and participate in everyday activities. By better understanding quality of life in childhood vision impairment, and the modifiable factors affecting their quality of life, changes to habilitation and rehabilitation services can be made to better support and personalize the care provided for these children and their families. ${ }^{4}$ However, the effects of vision impairment in the quality of life of children have been less explored in ophthalmologic research.

Quality of life questionnaires specifically for children with visual impairment have been developed and published. These questionnaires include the Children's Visual Function Questionnaire (CVFQ), LV Prasad Functional Vision Questionnaire (LVP-FVQ), and the Impact of Visual Impairment in Children (IVI_C). These questionnaires were developed to measure the impact of disease or treatment on a patient's life and self-esteem, performance in daily activities, social interactions, emotional well-being, and independence. ${ }^{4-6}$

Lee et al. (2016) translated to Filipino and validated the CVFQ3 Plus for children ages 3 to 7 years. Parents and primary caregivers of children aged 3 to 7 years with vision impairments answered the questionnaire. The CVFQ3 Plus Filipino version is highly reliable with high internal consistency helpful in accurately assessing the quality of life of children in the Philippine setting. ${ }^{7}$ Buño et al. compared the QoL scores of children aged 3 to 7 years old with visual impairments and the control group using the CVFQ3 Plus Filipino version. The results showed that children with visual impairments had significantly lower total index QoL score, general vision, competence, and personality subscale scores than the control group. No significant difference was found in the QoL scores for the general health, family impact, and treatment subscales. ${ }^{8}$

Gothwal et al. reported that none of the pediatric vision-related questionnaires have been developed from focus groups that reflect the opinion and experiences of the population of concern, as questionnaires relied on the opinion of experts or caregivers. Proxy opinion is recognized as a serious limitation to an accurate interpretation of quality of life. Therefore, there is a need for a user-defined tool to describe and quantify the impact of vision impairment for children. ${ }^{5}$

The Impact of Vision Impairment for Children (IVI_C) is a vision-specific pediatric instrument designed to assess the effects of visual impairment on the quality of life in children aged 8 to 18 years who have no additional disabilities. It is used to assess the needs of children with low vision and outcomes of interventions by deriving answers from both children and their caregivers. Originally developed in Australia, it is the most widely translated and validated tool in assessing the quality of life of children with visual impairment in many countries including India, Fiji, Malawi, and the United States. ${ }^{6}$ The IVI_C was translated into Filipino and validated in an unpublished study by Sipin et al. (2017). It identified domains useful in detecting problems in visual defects and related to mobility (travel and access to the environment), interaction (how the child interacts with non-vision-impaired peer group and people in the broader community), school (aspects of school-life and classroom activity), and emotion (the emotional impact of vision impairment on day-to-day life). ${ }^{9}$

The general objective of this study was to determine the effect of visual impairment on the quality of life of children aged 8 to 18 years. The specific objectives of the study were:

1. to determine the VI-QoL scores of children with visual impairment in terms of total VI-QoL score, as well as the subscales with the following domains: mobility, interaction, school, and emotion

2. to determine whether there is a significant difference in VI-QoL scores of children aged 8-18 years in terms of the subscale scores for the following domains mobility, interaction, school, and emotion

3. to determine the association between VI-QoL and the following factors: patient's age, sex, educational attainment and visual acuity, parents' or caregiver's educational attainment, occupation, socioeconomic status, full-time/part-time parenting/ caregiving

\section{METHODS}

This is an observational, analytical, cross-sectional study conducted at the Outpatient Department of the University of the Philippines-Philippine General Hospital, Sentro Oftalmologico Jose Rizal (SOJR), General and Pediatric Ophthalmology Clinics. This study was approved by the UP PGH Technical Review Board and the Ethics Review Board before research activities were initiated.

We included children 8 to 18 years of age with best corrected visual acuity of less than or equal to $20 / 40$ in the better-seeing eye for the visually impaired (VI) group. The control group included children aged 8 to 18 years with best corrected visual acuity of 20/20 to 20/30 in both eyes. Patients in the VI group were further categorized as those with mild visual impairment (defined as best corrected visual acuity of $20 / 50$ to $20 / 125$ on one eye and $20 / 20$ to $20 / 40$ on the other eye), moderate visual impairment (defined as best corrected visual acuity of 20/50 to 20/125 on both eyes), severe visual impairment (defined as best corrected visual acuity of $20 / 200$ or less on one eye, and $20 / 50$ to $20 / 125$ on the other eye), and severe bilateral visual impairment (defined as best corrected visual acuity of 20/200 or less on both eyes). 
All children were 8 to 18 years of age, able to read, write, and speak in Filipino. They were patients of the General Clinic and Pediatric Ophthalmology Clinic of the Philippine General Hospital for at least 1 year. Children who understood Filipino but were unable to read or write because of their visual impairment and children with other physical impairments other than their visual impairment were excluded from the study.

Participants of the study were recruited from the Sentro Oftalmologico Jose Rizal General Clinic and the Pediatric Ophthalmology Clinic. Parents of children who matched the inclusion criteria were requested to participate in the study.

The primary investigator explained the purpose, significance, study procedures and their responsibilities in the study. After patients concurred to participate, informed consent was acquired from the caregivers, and assent from the participants. Participants from the study were notified that they can withdraw anytime from the study without penalty.

Participants underwent a complete ophthalmologic examination, including the determination of visual acuity using the Early Treatment Diabetic Retinopathy Study (ETDRS) chart prior to administration of the Filipino version of IVI_C questionnaire (Appendix).

After ophthalmologic examination and prior to end of the medical consultation, the investigator administered the questionnaire on the children and their parents.

The following data were collected through interviews: patient's initials, age, sex, address, contact number, educational level. A medical chart review was done to obtain information regarding patients' clinical diagnosis and previous treatments. There was no monetary compensation given to study participants.

\section{Data Analysis}

A minimum total of 128 patients were required for this study based on a level of significance of $5 \%$ and a power of $80 \%$ with an absolute effect size of 0.5 .

Descriptive statistics was used to summarize the general and clinical characteristics of the participants. Frequency and proportion were used for nominal variables, median and range for ordinal variables, and mean and standard deviation for interval/ratio variables.

Independent T-test, Mann-Whitney U test, and Fisher's exact/Chi-square test were used to determine the difference of mean, median and frequency between groups, respectively. T-test was used to compare the total QoL score and subscale scores between VI group and control group. The significance level was set at $5 \%(\mathrm{p}<0.05)$.

Multivariate regression analysis was used to assess the effect of other variables such as age, sex, visual acuity and educational attainment, on the QoL scores in children with visual impairment.

All valid data were included in the analysis. Missing data were neither replaced nor estimated. Null hypothesis was rejected at $0.05 \alpha$ level of significance. Stata 15.0 was used for data analysis.

\section{RESULTS}

A total of 133 participants were included in the study, 67 in the visually impaired group and 66 in the control group. Participants had a median age of 10 years (range, 8 to 18 ) and $54 \%$ were female. Around three fourths of the participants were in elementary school (72.18\%), some were in high school (27.07\%), and one (0.75\%) was in college. Parents of the participants were mostly high school graduates (79.70\%), unemployed (81.95\%), of low socioeconomic status (93.23\%), and were full time parents (77.44\%). There was no difference in the demographic data of the children with visual impairment and the children in the control group (Table 1).

Regressed retinopathy of prematurity was the most common diagnosis for the visually-impaired (VI) group (14.93\%), while error of refraction was the most common diagnosis in the control group (42.42\%) (Table 2).

Overall quality of life scores, and across the domain subscores, were significantly lower in the visually impaired group compared to the control group (Table 3).

The mean total and domain IVI_C scores progressively declined with an increasing severity of visual impairment (Table 4). The mean $( \pm$ SD) total score ranged from 56 \pm 6 in the mildly impaired to $42 \pm 8$ in the severe bilateral impairment group.

On simple linear regression, severity of visual impairment was significantly associated with lower quality of life scores. Patients with visual impairment had lower quality of life scores by 33.466 points compared to the control group $(\mathrm{p}<0.001)$. Predictors of quality of life in children were visual impairment, age, sex, education, parent or caregiver's educational attainment, occupation, socioeconomic status, full time or part time parenting, shown in Table 5.

In the final model, the significant predictors of quality of life were visual impairment and age (Table 6). Quality of life scores of children with visual impairment was lower by 33.59 (95\% CI -35.82 points to -31.36 points) than those in the control group. The quality-of-life score increased by 0.579 per one unit increase in age. This model explained $87.05 \%$ of the variance in the quality-of-life scores $(\mathrm{p}<0.01)$.

\section{Interpretation of Results (per questionnaire item analysis)}

All questions in the mobility domain are statistically significant when compared by visually impaired group versus the control group (Table 7). Compared to most visually impaired respondents (43.3\%) who said that they sometimes found it hard to go down the stairs or to step off a walkway, most (71.2\%) of those in the control never did. Most respondents in the control group (65.2\%) were always confident that they could make their way to school 
Effects of Visual Impairment on the Quality of Life of Children Aged 8 to 18 Years

Table 1. Socio-demographic characteristics of children and parents $(n=133)$

\begin{tabular}{|c|c|c|c|c|}
\hline & $\begin{array}{c}\text { Total } \\
(n=133)\end{array}$ & $\begin{array}{l}\text { With visual impairment } \\
\qquad(\mathrm{n}=67)\end{array}$ & $\begin{array}{c}\text { Control group } \\
(n=66)\end{array}$ & p-value \\
\hline & \multicolumn{3}{|c|}{ Median (Range); Frequency (\%) } & \\
\hline \multicolumn{5}{|l|}{ Children } \\
\hline Age (years) & $10(8-18)$ & $10(8-18)$ & $10(8-18)$ & $0.590^{*}$ \\
\hline Sex & & & & $0.658^{\dagger}$ \\
\hline Male & $61(45.86)$ & $32(47.76)$ & $29(43.94)$ & \\
\hline Female & $72(54.14)$ & $35(52.24)$ & $37(56.06)$ & \\
\hline Education & & & & $1.000^{\ddagger}$ \\
\hline Elementary & $96(72.18)$ & $48(71.64)$ & $48(72.73)$ & \\
\hline Highschool & $36(27.07)$ & $18(26.87)$ & $18(27.27)$ & \\
\hline College & $1(0.75)$ & $1(1.49)$ & 0 & \\
\hline \multicolumn{5}{|l|}{ Parent } \\
\hline Education & & & & $0.328^{\ddagger}$ \\
\hline Elementary & $8(6.02)$ & $2(2.99)$ & $6(9.09)$ & \\
\hline High school & $106(79.70)$ & $56(83.58)$ & $50(75.76)$ & \\
\hline College & $19(14.29)$ & $9(13.43)$ & $10(15.15)$ & \\
\hline Occupation & & & & $0.682^{\dagger}$ \\
\hline Unemployed & $109(81.95)$ & $54(80.60)$ & 55 (83.33) & \\
\hline Employed & $24(18.05)$ & $13(19.40)$ & $11(16.67)$ & \\
\hline Socioeconomic status & & & & $1.000^{\ddagger}$ \\
\hline Low & $124(93.23)$ & $62(92.54)$ & 62 (93.94) & \\
\hline Middle & $9(6.77)$ & $5(7.46)$ & $4(6.06)$ & \\
\hline Parenting & & & & $0.231^{\dagger}$ \\
\hline Part time & $30(22.56)$ & $18(26.87)$ & 12 (18.18) & \\
\hline Full time & $103(77.44)$ & $49(73.13)$ & $54(81.82)$ & \\
\hline
\end{tabular}

*Mann Whitney U test; ${ }^{+}$Chi-square test; ${ }^{\ddagger}$ Fisher's Exact test

Table 2. Visual impairment diagnoses

\begin{tabular}{lccc} 
& $\begin{array}{c}\text { Total } \\
(\mathbf{n}=133)\end{array}$ & $\begin{array}{c}\text { With visual impairment } \\
(\mathbf{n}=67)\end{array}$ & $\begin{array}{c}\text { Control group } \\
(\mathbf{n}=66)\end{array}$ \\
\cline { 2 - 4 } & $2(1.5)$ & Frequency (\%) & 0 \\
Ametropic amblyopia & $2(1.5)$ & $2(2.99)$ & 0 \\
Anisometropic amblyopia & $1(0.75)$ & $2(2.99)$ & 0 \\
Chronic uveitis & $1(0.75)$ & $1(1.49)$ & 0 \\
Congenital aniridia & $1(1.49)$ & 0 \\
Congenital cataract & $5(3.76)$ & $5(7.46)$ & 0 \\
Congenital glaucoma & $3(2.26)$ & $3(4.48)$ & 0 \\
Congenital nystagmus & $4(3.01)$ & $4(5.97)$ & 0 \\
Corneal scar & $2(1.5)$ & $2(2.99)$ & $3(4.55)$ \\
Developmental cataract & $10(7.52)$ & $7(10.45)$ & 0 \\
Dislocated lens & $1(0.75)$ & $1(1.49)$ & $28(42.42)$ \\
Error of refraction & $36(27.07)$ & $8(11.94)$ & $2(2.99)$ \\
Infantile esotropia & $1(0.75)$ & 0 & $13(19.7)$ \\
Intermittent exotropia & 17 & $4(5.97)$ & 0 \\
Microcornea & $1(0.75)$ & $1(1.49)$ & 0 \\
Optic nerve atrophy & $1(0.75)$ & $1(1.49)$ & 0 \\
Optic Nerve Coloboma & $2(1.5)$ & $2(2.99)$ & $3(4.55)$ \\
Pathologic myopia & $4(3.01)$ & $1(1.49)$ & $17(25.76)$ \\
Refractive accommodative esotropia & 20 & $3(4.48)$ & 0 \\
Regressed retinopathy of prematurity & $10(7.52)$ & $10(14.93)$ & 0 \\
Sensory deprivational amblyopia & $7(5.26)$ & $7(10.45)$ & 0 \\
Traumatic cataract & $2(1.5)$ & $2(2.99)$ & \\
\hline
\end{tabular}


Table 3. Quality of life of children, comparing visually impaired and normal vision $(n=133)$

\begin{tabular}{|c|c|c|c|c|c|}
\hline & \multirow{2}{*}{$\begin{array}{l}\text { Maximum } \\
\text { Score }\end{array}$} & Total $(n=133)$ & With visual impairment $(n=67)$ & Control group $(n=66)$ & \multirow{2}{*}{$p$} \\
\hline & & \multicolumn{3}{|c|}{ Mean \pm SD } & \\
\hline Total QoL & 90 & $66.38 \pm 18.07$ & $49.78 \pm 8.44$ & $83.24 \pm 4.18$ & $<0.001$ \\
\hline Mobility & 24 & $14.71 \pm 5.41$ & $10.15 \pm 3.50$ & $19.35 \pm 1.93$ & $<0.001$ \\
\hline Interaction & 36 & $25.42 \pm 6.85$ & $19.30 \pm 3.58$ & $31.64 \pm 2.09$ & $<0.001$ \\
\hline School & 28 & $20.72 \pm 4.78$ & $16.45 \pm 2.37$ & $25.06 \pm 1.63$ & $<0.001$ \\
\hline Emotion & 8 & $5.53 \pm 2.04$ & $3.88 \pm 1.50$ & $7.20 \pm 0.73$ & $<0.001$ \\
\hline
\end{tabular}

Statistical Test Used: Independent t-test

Table 4. IVI_C total and subscale scores, by severity of visual impairment $(n=67)$

\begin{tabular}{|c|c|c|c|c|c|}
\hline & Mild (n=21) & Moderate (n=17) & Severe Unilateral $(n=17)$ & Severe Bilateral $(n=12)$ & \multirow{2}{*}{$p$} \\
\hline & \multicolumn{4}{|c|}{ Mean \pm SD } & \\
\hline Total & $56.14 \pm 5.89$ & $49.29 \pm 7.63$ & $47.88 \pm 6.81$ & $42 \pm 7.94$ & $<.001$ \\
\hline Mobility & $12 \pm 3.14$ & $9.71 \pm 3.31$ & $10 \pm 3.26$ & $7.75 \pm 3.28$ & 0.006 \\
\hline Interaction & $21.52 \pm 3.33$ & $19.24 \pm 3.33$ & $18.53 \pm 2.85$ & $16.58 \pm 2.85$ & 0.001 \\
\hline School & $18.29 \pm 1.71$ & $16.24 \pm 2.39$ & $15.47 \pm 2.21$ & $14.92 \pm 1.73$ & $<.001$ \\
\hline Emotion & $4.33 \pm 1.77$ & $4.12 \pm 1.50$ & $3.88 \pm 0.93$ & $2.75 \pm 1.22$ & 0.024 \\
\hline
\end{tabular}

Statistical Test Used: One-way ANOVA

Table 5. Predictors of QoL of children with visual impairment ( $n=133$ )

\begin{tabular}{|c|c|c|}
\hline & $\begin{array}{l}\text { Crude Beta Coefficient } \\
\text { (95\% Cl) }\end{array}$ & $p$-value \\
\hline VI group & $-33.466(-35.66$ to -31.18$)$ & $<0.001$ \\
\hline \multicolumn{3}{|l|}{ Patient characteristics } \\
\hline Age (years) & $0.349(-0.76$ to 1.46$)$ & 0.536 \\
\hline \multicolumn{3}{|l|}{ Sex } \\
\hline Male & Reference & \\
\hline Female & $0.799(-5.44$ to 7.04$)$ & 0.800 \\
\hline \multicolumn{3}{|l|}{ Education } \\
\hline Elementary & Reference & - \\
\hline High school and college & $1.266(-5.67$ to 8.20$)$ & 0.719 \\
\hline \multicolumn{3}{|c|}{ Parent/Caregiver characteristics } \\
\hline \multicolumn{3}{|c|}{ Education } \\
\hline Elementary & Reference & - \\
\hline High school and college & $-6.508(-19.54$ to 6.53$)$ & 0.325 \\
\hline \multicolumn{3}{|l|}{ Occupation } \\
\hline Unemployed & Reference & - \\
\hline Employed & $-1.159(-6.93$ to 9.25$)$ & 0.777 \\
\hline \multicolumn{3}{|l|}{ Socioeconomic status } \\
\hline Low & Reference & - \\
\hline Middle & $-1.484(-13.87$ to 10.90$)$ & 0.813 \\
\hline \multicolumn{3}{|l|}{ Parenting } \\
\hline Part time & Reference & - \\
\hline Full time & $2.604(-4.82$ to 10.03$)$ & 0.489 \\
\hline
\end{tabular}

Table 6. Predictors of QoL of children with visual impairment $(n=133)$

\begin{tabular}{lcc} 
& Crude Beta Coefficient $(95 \% \mathrm{Cl})$ & p-value \\
VI group & $-33.590(-35.82$ to -31.36$)$ & $<0.001$ \\
Age & $0.579(0.18$ to 0.98$)$ & 0.005 \\
\hline
\end{tabular}

Adjusted $R^{2}=87.05 \% ; p<0.001$ by themselves, while most visually impaired respondents (35.8\%) only do sometimes. Most respondents in the control group (60.6\%) were almost always confident using public transport by themselves, while most of those with visual impairments only do sometimes (35.8\%). Three fourths (75.8\%) of respondents without visual impairments almost always felt confident in places they do not know, while $40.3 \%$ of those with visual impairments only did sometimes. Most respondents without visual impairments $(62.1 \%)$ were almost always confident moving around spaces they did not know in the daytime, while $54.6 \%$ said the same during the night. In comparison, most respondents with visual impairments (43.3\%) were only sometimes confident during the daytime, while $36.1 \%$ were sometimes confident at night.

All questions included in the interaction domain are statistically significant when compared by visually impaired group versus the control group (Table 8). Most respondents with visual impairments (52.24\%) almost always found their friends on the playground during lunch and playtime, while most respondents (87.88\%) without visual impairments always did. Most respondents with visual impairments (47.76\%) almost always recognized people they know before they spoke to them, while most respondents without visual impairments always did (69.7\%). More than half (62.69\%) of respondents with visual impairments can sometimes participate in games or sports that they want to play with their friends, while most respondents in the control group (54.55\%) almost always did. More than three fourths of respondents with visual impairments (76.13\%) sometimes got the chance to do other social activities besides sports, while most respondents in the control (53.03\%) almost always did. Most respondents with visual impairments (61.19\%) sometimes said that their eyesight has stopped them from doing things they want to do, while most respondents in the 
Table 7. Impact of vision impairment for children, mobility domain

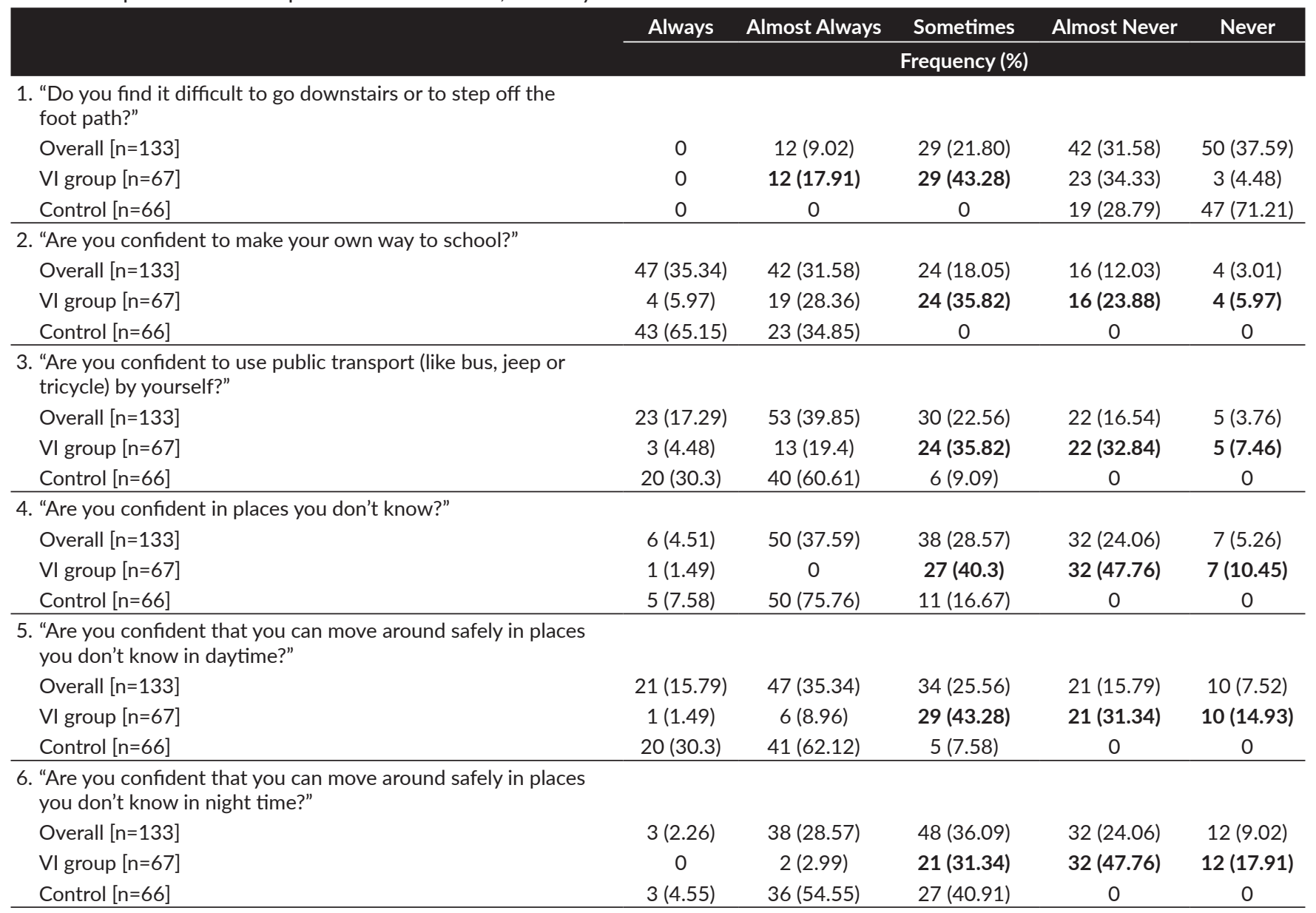

All mobility questions are statistically significant when compared by visual impairment vs control groups $(p<0.05)$.

control group (62.12\%) said that this happened almost never. Most respondents with visual impairments (49.25\%) said that other students sometimes helped them when they ask, while most respondents in the control group (57.58\%) said that others almost always did. Most respondents who were visually impaired $(64.18 \%)$ said that other students help them join in, while most respondents in the control group (51.52\%) said that others almost always did. Most respondents with visual impairments $(64.18 \%)$ said that they sometimes found it hard to join other students, while most respondents in the control (63.64\%) said that they almost never did. More than two thirds of respondents with visual impairments (65.67\%) sometimes felt frustrated, while more than half $(51.52 \%)$ of those in the control almost never did.

All questions in the school domain are statistically significant when compared by visually impaired group versus the control group (Table 9). Most respondents with visual impairments $(62.7 \%)$ said that other students sometimes understood their special needs, while two thirds of respondents in the control said that others almost always did. Most respondents with visual impairments (58.2\%) said that teachers almost always understood their special needs, while most respondents in the control (68.2\%) said that teachers always did. Most respondents who were visually impaired (56.7\%) say that they saw and got all the same information as other students in the classroom, while most respondents in the control (59.1\%) said that they always did. Most respondents with visual impairments (62.7\%) said that they sometimes got all the information at the same time as other students, while most respondents without visual impairments (57.6\%) said that they always did. While some respondents with visual impairments $(47.8 \%)$ say that they sometimes got sufficient time in school to complete the work laid down by their teacher, some (47.8\%) say that they almost always did, while more than three fourths of respondents without visual impairments $(77.3 \%)$ said that they always did. Half of the respondents with visual impairments (50.8\%) said that they sometimes feel confident asking for the help they need in the classroom, while most respondents in the control (53.0\%) say that they always did. Most respondents with visual impairments $(61.2 \%)$ say that when they asked for help, people sometimes understood how much help they need, while most respondents without visual impairments (57.6\%) say that others always did. 
Table 8. Impact of vision impairment for children, mobility domain

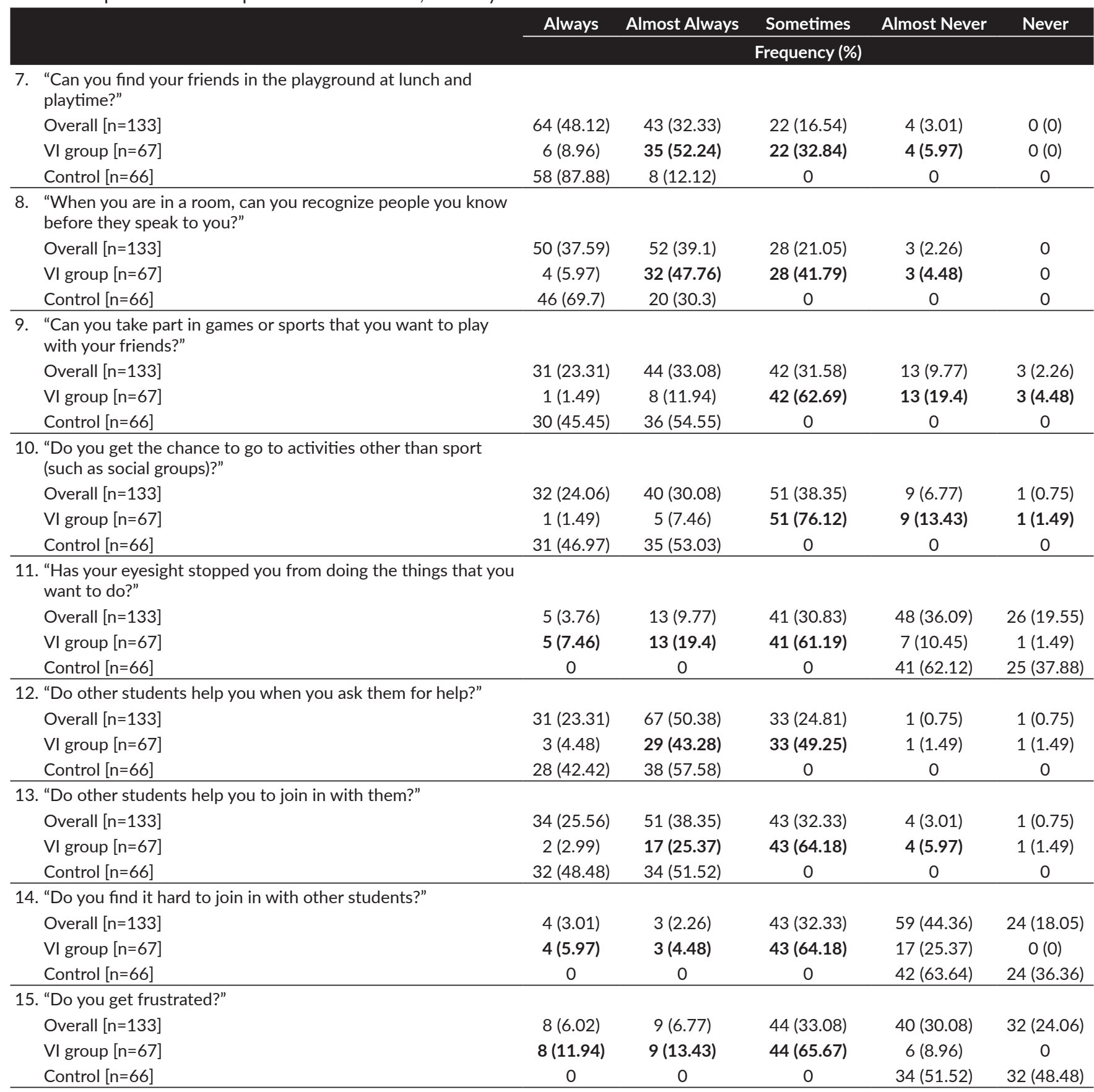

All interaction questions are statistically significant when compared by visual impairment vs control groups $(p<0.05)$.

All questions in the emotion domain are statistically significant when compared by visually impaired group versus the control group (Table 10). While most respondents with visual impairments (44.8\%) said that people sometimes told them that they cannot do the things that they want to do, most respondents in the control group (56.1\%) said this never happened. While most respondents with visual impairments (55.2\%) said that people sometimes stopped them from doing the things they wanted to do, most respondents in the control (63.6\%) say that people never did.

\section{DISCUSSION}

Our results showed that overall quality of life scores and sub scores across domains, were significantly lower in the visually impaired group compared to the control group. Similarly, the mean total and domain IVI_C scores progressively declined with an increasing severity of visual impairment. On multivariate analysis, the significant predictors of quality of life were visual impairment and age. Quality of life scores of children with visual impairment is less by 
Effects of Visual Impairment on the Quality of Life of Children Aged 8 to 18 Years

Table 9. Impact of Vision Impairment for Children, school domain

\begin{tabular}{|c|c|c|c|c|c|}
\hline & Always & Almost Always & Sometimes & Almost Never & Never \\
\hline & \multicolumn{5}{|c|}{ Frequency (\%) } \\
\hline \multicolumn{6}{|c|}{ 16. "Do other students understand your special needs?" } \\
\hline Overall [n=133] & $22(16.54)$ & $63(47.37)$ & $42(31.58)$ & $3(2.26)$ & $3(2.26)$ \\
\hline VI group [n=67] & $0(0)$ & $19(28.36)$ & $42(62.69)$ & $3(4.48)$ & $3(4.48)$ \\
\hline Control $[n=66]$ & $22(33.33)$ & $44(66.67)$ & 0 & 0 & 0 \\
\hline \multicolumn{6}{|c|}{ 17. "Do your teachers understand your special needs?" } \\
\hline Overall [n=133] & $58(43.61)$ & $60(45.11)$ & $13(9.77)$ & $2(1.5)$ & 0 \\
\hline VI group [n=67] & $13(19.4)$ & 39 (58.21) & $13(19.4)$ & $2(2.99)$ & 0 \\
\hline Control $[n=66]$ & $45(68.18)$ & $21(31.82)$ & 0 & 0 & 0 \\
\hline \multicolumn{6}{|c|}{$\begin{array}{l}\text { 18. "In the classroom, do you see and get all the same information } \\
\text { as other students?" }\end{array}$} \\
\hline Overall [n=133] & $41(30.83)$ & 44 (33.08) & $38(28.57)$ & $9(6.77)$ & $1(0.75)$ \\
\hline VI group [n=67] & 2 (2.99) & $17(25.37)$ & $38(56.72)$ & $9(13.43)$ & $1(1.49)$ \\
\hline Control $[n=66]$ & $39(59.09)$ & $27(40.91)$ & 0 & 0 & 0 \\
\hline \multicolumn{6}{|c|}{$\begin{array}{l}\text { 19. "Do you get all the information at the same time as the other } \\
\text { students?" }\end{array}$} \\
\hline Overall [n=133] & $38(28.57)$ & $42(31.58)$ & $42(31.58)$ & $11(8.27)$ & 0 \\
\hline VI group [n=67] & $0(0)$ & $14(20.9)$ & 42 (62.69) & $11(16.42)$ & 0 \\
\hline Control $[n=66]$ & $38(57.58)$ & $28(42.42)$ & 0 & 0 & 0 \\
\hline \multicolumn{6}{|c|}{$\begin{array}{l}\text { 20. "Do you get enough time in school to complete the work set } \\
\text { by teacher?" }\end{array}$} \\
\hline Overall [n=133] & $52(39.1)$ & 47 (35.34) & $32(24.06)$ & $2(1.5)$ & 0 \\
\hline VI group [n=67] & $1(1.49)$ & 32 (47.76) & 32 (47.76) & $2(2.99)$ & 0 \\
\hline Control $[n=66]$ & $51(77.27)$ & $15(22.73)$ & 0 & 0 & 0 \\
\hline \multicolumn{6}{|c|}{$\begin{array}{l}\text { 21. "When you are in the classroom, are you confident about } \\
\text { asking for help you need?" }\end{array}$} \\
\hline Overall [n=133] & $39(29.32)$ & $57(42.86)$ & $34(25.56)$ & $2(1.5)$ & $1(0.75)$ \\
\hline VI group [n=67] & $4(5.97)$ & $26(38.81)$ & 34 (50.75) & $2(2.99)$ & $1(1.49)$ \\
\hline Control $[n=66]$ & $35(53.03)$ & $31(46.97)$ & 0 & 0 & 0 \\
\hline \multicolumn{6}{|c|}{$\begin{array}{l}\text { 22. "When you ask for help, do people understand how much help } \\
\text { you need?" }\end{array}$} \\
\hline Overall [n=133] & $39(29.32)$ & 48 (36.09) & $41(30.83)$ & 4 (3.01) & $1(0.75)$ \\
\hline VI group [n=67] & 1 (1.49) & $20(29.85)$ & 41 (61.19) & $4(5.97)$ & $1(1.49)$ \\
\hline Control $[n=66]$ & $38(57.58)$ & $28(42.42)$ & 0 & 0 & 0 \\
\hline
\end{tabular}

All school questions are statistically significant when compared by visual impairment vs. control groups $(p<0.05)$.

Table 10. Impact of Vision Impairment for Children, school domain

\begin{tabular}{|c|c|c|c|c|c|}
\hline & Always & Almost Always & Sometimes & Almost Never & Never \\
\hline & \multicolumn{5}{|c|}{ Frequency (\%) } \\
\hline \multicolumn{6}{|c|}{$\begin{array}{l}\text { 23. "Do people tell you that you can't do the things that you want } \\
\text { to do?" }\end{array}$} \\
\hline Overall [n=133] & $4(3.01)$ & $15(11.28)$ & $30(22.56)$ & $46(34.59)$ & $38(28.57)$ \\
\hline VI group [n=67] & $4(5.97)$ & $15(22.39)$ & 30 (44.78) & $17(25.37)$ & $1(1.49)$ \\
\hline Control $[n=66]$ & 0 & 0 & 0 & $29(43.94)$ & $37(56.06)$ \\
\hline \multicolumn{6}{|c|}{ 24. "Do people stop you from doing the things you want to do?" } \\
\hline Overall [n=133] & $3(2.26)$ & $13(9.77)$ & $37(27.82)$ & $37(27.82)$ & $43(32.33)$ \\
\hline VI group [n=67] & $3(4.48)$ & $13(19.4)$ & 37 (55.22) & $13(19.4)$ & $1(1.49)$ \\
\hline Control $[n=66]$ & 0 & 0 & 0 & $24(36.36)$ & $42(63.64)$ \\
\hline
\end{tabular}

Both emotion questions are statistically significant when compared by visual impairment vs control groups $(p<0.05)$. 
33.59 (95\% CI -35.82 points to -31.36 points) than those in the control group. The quality of life increases by 0.579 per one unit increase in age. This model explained $87.05 \%$ of the variance in the scores $(\mathrm{p}<0.01)$. All the domains were significantly affected despite the difference in severity of visual impairment; with interaction being the most affected and emotion being the least affected.

Similar results were reported by Buño, et. al. in children aged 3-7 years, which showed that visual impairment had a negative effect on the quality of life of Filipino children, especially those with poorer best corrected acuity, affecting their visual health, personality, and competence in doing daily activities. ${ }^{8}$ In addition, visually-impaired patients show a decreased adaptive behavior across domains of practical, social, and conceptual function. These results mirror earlier studies supporting the decreased adaptive behavior in schoolage children and in adolescents with visual impairment. ${ }^{10}$

Our results show that specific subdomains of interaction, school experience, and mobility were significantly different between VI and non-VI groups. These subdomains are likely closely related. Poor visual acuity is related to poor stereopsis in children causing poor performance on activities involving hand-eye coordination. It can also affect other clinical factors such as contrast sensitivity, reading speed, and visual fields that can further affect the mobility. The deficiency in mobility and self-care can lead to problems in social integration, thereby promoting social isolation. ${ }^{11}$

Older children and adolescents had better scores than younger patients. This may be due to adaptation. Adaptation to the vision impairment develops over time, and children improve in coping and maintaining everyday competence as they grow older. However, other studies suggest otherwise, with older children having poorer quality of life. According to Chadha et al., increasing age, even when visual acuity remains essentially unchanged, the demands made upon the visual system increases (e.g., the requirement to read smaller print, to drive). They postulated that an increasing inability to meet these demands would result in a poor quality of life. The varying results may probably be attributed to the difference in questionnaire used, processes and instructions. In their study, they had utilized a Low Vision Quality of Life Questionnaire which they found less specific, leading to a suggestion to make use of a specifically designed, ageappropriate questionnaire that the children can complete independently, such as the recently developed Cardiff Visual Ability Questionnaire (CVAQC) 23 or the IVI_C,17. ${ }^{1}$

A significant proportion of visually impaired children involved in this study had regressed retinopathy of prematurity, followed by errors of refraction, and sensory deprivational amblyopia. These results concur with the study of Del Mundo et al., which reported that retinal disorders accounted for more than half of the anatomic causes of severe visual impairment and blindness in the Philippines (69.8\%), most of these were due to retinopathy of prematurity (47.7\%). ${ }^{12}$ Additional studies on the quality of life of visually impaired patients within the age range who have undergone refractive correction, surgeries, and other ocular management to address their conditions could provide good outcomes on enhancement of quality of life of visually impaired patients. The study by Ezinne et. al. observed the growing prevalence of relatively high refractive error and visual impairment among primary school children with uncorrected error of refraction accounting for $86.6 \%$ of all causes of visual impairment. They highlighted the need for services and strategies to address these concerns. The most prevalent error of refraction is myopia (46.4\%), second is astigmatism (36.1\%) and last is hyperopia (17.5\%). Uncorrected error of refraction and vision impairment were notably more prevalent in females than males, in 11 to 13 years of age. Visual impairment was notably seen to be greatest in children 5 to 7 years of age. ${ }^{13}$ In Shanghai, China, the prevalence of myopia was lower or comparable to that reported findings in other populations from age 3 to 5 years, and increases dramatically after 6 years, consistent with the belief of a strong environmental role of schooling on myopia development. ${ }^{14}$ Errors of refraction can be effectively and easily managed with prescription eyeglasses, contact lenses, with prescription eyeglasses being the most common and cost-effective form of treatment.

All children go through the process of social skills development, as well as those with vision problems. ${ }^{15}$ To understand the impact of visual impairment on a child's quality of life, we must consider factors in their development such as learning experience in the early stages, family members' support and guidance for them to adapt to their environment. Children with visual impairment were observed to have difficulty in adjusting to their environment and therefore have limitations in gaining experience through interaction. The impact of visual impairment in children in terms of interaction in the results of this research show that visually impaired children struggle with joining other students, while none in the control group experienced this. Difficulties in the social domain may arise due to multiple influences. First, social cognition may develop differently in children with visual impairment, potentially because salient social information such as facial expressions are less accessible to children with congenital visual impairment. Our results also showed that there are times that children with visual impairment cannot find their friends during playtime or they did not recognize people they were familiar with, while the control group did not struggle with this. Other constraints may also arise from reduced opportunities for social interaction. For instance, children with visual impairment have been found to participate less in activities with their peers and may be driven by peer rejection or exclusion from mainstream activities such as sports. Reduced mobility and independence may introduce additional boundaries that make it difficult for children with visual impairment to take part in age-typical social activities with their peers. ${ }^{3}$ Our results showed that visually impaired children were prevented by parents or caregivers from doing what they wanted to do 
because of their vision, even if they said that at times, they were never excluded from being given a chance to participate in social gatherings or activities.

Acquiring social skills is not natural for visually impaired children, but it requires training and nurturing throughout the educational years. It is important that teachers must understand the factors that influence or impede the development of these children. The school environment should ideally help the visually impaired children in their social behavior. The opportunities for social-skills instruction should not be limited by the curriculum; teachers and parents should identify learning goals based on realistic expectations for individual children. With realistic learning goals, and social acceptance, students with visual impairment will be able to interact effectively with sighted peers and adults, and make independent decisions, to take responsibility for their actions, and to feel confident and successful within the environment.

A limitation of this study is that children who cannot read or write despite their ability to comprehend were excluded so that the data from the most visually impaired children were missed. We may be able to reasonably infer, however, that quality of life for this group may even be worse than that of the children included in our study.

We recommend that education, community participation, and assistive programs should be promoted so that changes to habilitation services can be made to better support and personalize the care provided for children and adolescents with visual impairment and their families.

\section{CONCLUSION}

Quality of life scores of visually impaired children are significantly lower than non-visually impaired children. Patients with visual impairment have reduced quality of life, and similarly, children with mild visual impairment showed better quality of life compared to patients with moderate and severe visual impairment. All domains were significantly affected despite the difference in severity of visual impairment. Younger children with visual impairment have significantly lower quality of life compared to older children with visual impairment.

\section{Statement of Authorship}

All authors contributed in the conceptualization of work; acquisition and analysis of data; drafting and revising; and final approval of the version to be published.

\section{Author Disclosure}

All authors declared no conflicts of interest.

\section{Funding Source}

This study has no funding support.

\section{REFERENCES}

1. Chadha RK, Subramanian A. The effect of visual impairment on quality of life in children aged 3-16 years. Br J Ophthalmol. 2010; 95(5):642-5

2. De Carlo DK, McGwin G, Bixler MA, Wallander J, Owsley C. Impact of pediatric vision impairment on daily life: results of focus groups. Optom Vis Sci. 2012 September; 89(9):1409-16

3. De Vries J, Van Heck GL1997. The World Health Organization Quality of Life Assessment Instrument (WHOQOL-100): Validation Study with the Dutch Version. Eur J Psychol Assess. 1997; 13(3): 164-78.

4. Birch E, Cheng C, Felius J. Validity and reliability of the Children's Visual Function Questionnaire (CVFQ). JAAPOS. 2007 October; 11(5):473-9.

5. Gothwal V, Sumalini R, Bharani S, Reddy S, Bagga D. The Second Version of the L.V. Prasad - Functional Vision Questionnaire. Optom Vis Sci. 2012 Nov; 89(11):1601-10.

6. Cochrane G, Marella M, Keeffe J, Lamoureux E. The Impact of Vision Impairment for Children (IVI_C): Validation of a Vision Specific Pediatric Quality of Life Questionnaire Using Rasch Analysis. Invest Ophthalmol Vis Sci. 2011 Mar; 52(3):1632-40.

7. Lee JA, Pajarillo AK, Santiago AP. Translation and validation of a Filipino version of the Children's Visual Function Questionnaire (CVFQ). Philipp J Ophthalmol.2018; 43(2):72-6.

8. Buño B, Pajarillo AK. Effects of visual impairment on quality of life of children aged 3 to 7 years. Philipp J Ophthalmol. 2019; 44(1):14-8.

9. Sipin S, Santiago AP, Pajarillo AK. Validation of the Impact of Vision Impairment for Children (IVI_C) among school children - In Filipino translation. (Unpublished).

10. Bathelt J, De Haan M, Dale N. Adaptive behavior and quality of life in school age children with congenital visual disorders and different levels of impairment. Res Dev Disabil. 2019; 85:154-62.

11. Verver SH, Vervloed MP, Steenbergen B. Facilitating play and social interaction between children with visual impairments and sighted peers by means of augmented toys. J Dev Phys Disabil. 2020 May; 32:93-111.

12. Del Mundo PS, Chua CE. Causes of blindness and severe visual impairment among children enrolled in an early intervention and preschool program of a school for the blind in the Philippines. Philipp J Ophthalmol. 2015 June; 40:41-2.

13. Ezinne NE, Mashige KP. Refractive error and visual impairment in primary school children in Onitsha, Anambra State, Nigeria. Afr Vision Eye Health. 2018; 77(1):544.

14. Ma Y, Qu X, Zhu X, Xu X, Zhu J, Sankaridurg P, et al. Age- specific prevalence of visual impairment and refractive error in children aged 3-10 years in Shanghai, China. Invest Ophthalmol Vis Sci. 2016; 57:6188-96.

15. Salleh N, Khalim, Zainal. Why the visually impaired students socially behave the way they do. Procedia Social and Behavioral Sciences. 2010 Dec: 9;859-63. 